\title{
Vitamin D binding protein variants associate with asthma susceptibility in the Chinese han population
}

Fei Li ${ }^{1}$ Lei Jiang ${ }^{1}$, Saffron A Willis-Owen², Youming Zhang ${ }^{2^{*}}$ and Jinming Gao ${ }^{{ }^{*}}$

\begin{abstract}
Background: Asthma is a genetically heterogeneous disease. Polymorphisms of genes encoding components of the vitamin D pathway have been reported to associate with the risk of asthma. We have previously demonstrated that vitamin D status was associated with lung function in Chinese asthma patients. In this study, we tested whether polymorphisms of genes encoding for vitamin D receptor (VDR), vitamin D 25-hydroxylase (CYP2R1) and vitamin D binding protein (GC) were associated with asthma in the Chinese Han population.
\end{abstract}

Methods: We sequenced all 8 exons of VDR and all 5 exons of CYP2R1 in a Chinese case-control cohort of asthma consisting of 467 cases and 288 unrelated healthy controls. Two mutations were identified in these regions. These variants were specified as rs2228570 in exon 2 of VDR and rs12794714 in exon 1 of CYP2R1. We also genotyped two common polymorphisms in GC gene (rs4588 and rs7041) by a PCR-restriction fragment length polymorphism (RFLP) method. We analyzed the association between these 4 polymorphisms and asthma susceptibility and asthma-related traits.

Results: Polymorphic markers in VDR and CYP2R1 were not associated with asthma in the Chinese Han cohort. Importantly, variants in GC gene, which give rise to the two most common electrophoretic isoforms of the vitamin $\mathrm{D}$ binding protein, were associated with asthma susceptibility. Compared with isoform Gc1, Gc2 was significantly associated with the risk of asthma ( $O R=1.35,95 \% \mathrm{Cl}=1.01-1.78 \mathrm{p}=0.006)$.

Conclusions: The results provide supporting evidence for association between GC variants and asthma susceptibility in the Chinese Han population.

\section{Background}

Asthma is a chronic inflammatory disease of the airways characterized by reversible airflow obstruction and airway hyper-reactivity. The disease exhibits complex patterns of transmission, and has an estimated heritability of $36-79 \%$ [1]. To date, a plethora of genes and variants have been implicated in the pathogenesis and progression of asthma [2,3]. However, relatively few of these genes and variants have been successfully replicated.

\footnotetext{
* Correspondence: y.zhang@imperial.ac.uk; gaojm@pumch.cn 'Department of Respiratory Diseases, Peking Union Medical College Hospital, Peking Union Medical College \& Chinese Academy of Medical Sciences, Beijing 100730, China

${ }^{2}$ Molecular Genetics and Genomics, National Heart and Lung Institute, Imperial College London, London, UK

Full list of author information is available at the end of the article
}

In recent years the vitamin $\mathrm{D}$ pathway has emerged as a new potential component of asthma and allergy susceptibility. The majority of this evidence has been derived from epidemiological surveys. Deficiency of vitamin D has been found to increase the risk of asthma or asthma exacerbation [4-8]; higher maternal vitamin D intake during pregnancy has been associated with a reduced risk of wheezing illnesses in young children [9-11]; and circulating 25-hydroxyvitamin D (25OHD) has been associated with lung function in patients with asthma $[7,12,13]$. More recently, a small randomized double-blinded 6 month trial indicated that vitamin D supplementation in children may reduce asthma exacerbation following acute respiratory infection [14].

At the genetic level, a number of polymorphisms have been identified in various components of the vitamin $D$ pathway; including the vitamin $\mathrm{D}$ receptor $V D R$, the

\section{Biomed Central}


microsomal vitamin D hydroxylase $C Y P 2 R 1$, and the vitamin D binding protein GC. VDR is the major receptor for the bioactive form of 25OHD, 1 $\alpha, 25$-dihydroxyvitamin D3 (1,25OHD). The gene encoding $V D R$ is located on human chromosome 12q13 and has 8 coding exons encode 427 amino acids. CYP2R1, positioned on human chromosome 11p15, is responsible for transforming photo-synthesized and dietary vitamin $\mathrm{D}$ into 25OHD [15]. CYP2R1 gene has 5 exons encoding 501 amino acids. Vitamin D metabolites in the circulation are bound to vitamin D binding protein (DBP) encoded by a highly polymorphic gene $G C$. GC is located on chromosome $4 \mathrm{q} 13$ and has 13 exons encoding 474 amino acids. There are two common functional single nucleotide polymorphisms (SNPs) in exon 11 of $G C$, which are rs4588 and rs7041 positioned at codons 416 and 420 . These variants have been associated with different binding affinity for $25 \mathrm{OHD}$, and give rise to the two most common electrophoretic isoforms of DBP; Gc1 (which can be further subdivided into Gc1F and Gc1S); and Gc2. Whilst GC isoforms have been implicated in chronic obstructive pulmonary disease (COPD) across a variety of contrasting population (for review, see reference 16), there is relatively little evidence of their involvement in asthma $[16,17]$. VDR variants have been extensively studied in asthma, although the results have shown contradictory [15,18-23]. Similarly, evidence for association between $C Y P 2 R 1$ variants and asthma has also been inconsistent between populations [15]. One potential explanation for this inconsistency may be differences in the underlying pattern of linkage disequilibrium between typed markers and the true disease loci in distinct populations.

We previously showed that lower vitamin D status in serum was associated with impaired lung function in Chinese asthma patients [12]. In this study we set out to evaluate whether the variants of genes encoding for the key components of vitamin D pathway, including CYP2R1,VDR, and DBP, were associated with asthma or asthma-related phenotypes in a case-control design study in the Chinese Han population.

\section{Methods}

\section{Subjects and phenotypical characteristics}

We recruited 467 asthma patients and 288 controls with Han ethnicity from the Northern region of China. All participants were unrelated. Asthma cases were recruited at the Pulmonary Clinic, Peking Union Medical College Hospital. Ethnicity-matched controls were selected from non-asthmatic, non-atopic, healthy individuals with normal lung function [24].

Measurement of serum total IgE was performed by applying the UniCAP System (Pharmacia, Uppsala, Sweden) according to the manufacturer's instructions.
Asthma was diagnosed using the criteria defined by international guideline [25]. All cases complained of current asthma symptoms including wheezing, cough, awakening at night and shortness of breath. Asthmatics with forced expiratory volume in $1 \mathrm{~s}\left(\mathrm{FEV}_{1}\right) \geq 170 \%$ of predicted underwent the methacholine challenge test, and positive bronchial hyperresponsiveness was defined by a $20 \%$ fall in $\mathrm{FEV}_{1}$ at inhaled methacholine concentrations $\leq 16 \mathrm{mg} / \mathrm{ml}$. Patients with $\mathrm{FEV}_{1}<70 \%$ of predicted underwent an airway reversibility test with positive airway reversibility defined by both $12 \%$ improvement in $\mathrm{FEV}_{1}$ and an increase $\geq 200 \mathrm{ml}$ in the absolute $\mathrm{FEV}_{1}$ value after $\beta_{2}$-agonist inhalation [25].

The incidence of asthma was higher in females than in males $(60.4 \%$ vs $39.6 \%)$. The baseline $\mathrm{FEV}_{1} \%$ predicted was significantly lower in asthmatics than normal controls $(68.9 \pm 37.9 \%$ vs $90.6 \pm 14.9 \%, P<0.001)$. Methacholine airway challenge test was performed in 224 (48\%) asthma subjects with baseline $\mathrm{FEV}_{1}>70 \%$ of predicted; in all of these subjects, positive bronchial hyperresponsiveness was documented. The airway reversibility test was carried out in 273 patients (58\%). The mean improvement in $\mathrm{FEV}_{1}$ was $26.4 \pm 14.3 \%$. The serum total IgE values in controls were within the normal range. Detailed characteristics of the individuals are listed in Table 1.

The study protocol was reviewed and approved by the Human Research Ethics Committee of the Peking Union Medical College Hospital, and all subjects gave written informed consent to participate in the study.

\section{SNPs selection and genotyping}

DNA samples (derived from 467 asthma patients and 288 healthy, non-atopic controls) were extracted from peripheral blood leukocytes using a standard phenolchloroform method.

All selected genes code for key enzymes or components responsible for vitamin D metabolic pathway. Single nucleotide polymorphisms (SNPs) of genes tested in this study have been associated with asthma

Table 1 Demographics of the participants

\begin{tabular}{lll}
\hline & Asthma $(\mathbf{n}=\mathbf{4 6 7})$ & Control $(\mathbf{n}=\mathbf{2 8 8})$ \\
\hline $\begin{array}{l}\text { Mean age, years } \\
\quad \text { Range }\end{array}$ & $40.8 \pm 14.1$ & $45.1 \pm 0.7$ \\
Sex, $\mathrm{n}(\%)$ & $18-76$ & $22-72$ \\
$\quad$ Male & $185(39.6)$ & $158(55.0)$ \\
$\quad$ Female & $282(60.4)$ & $130(45.0)$ \\
log $_{\mathrm{e}}$ gE, $\mathrm{U} / \mathrm{L}$ & $5.24 \pm 1.44$ & $3.64 \pm 1.10$ \\
Eosinophils,\% & $1.63 \pm 0.91$ & $2.19 \pm 0.93$ \\
Lung function & & \\
$\quad \mathrm{FEV}, \%$ & $68.94 \pm 37.88$ & $90.6 \pm 14.92$ \\
$\quad \mathrm{FEV}_{1} / \mathrm{FVC} \%$ & $63.93 \pm 14.91$ & $81.53 \pm 9.52$ \\
\hline
\end{tabular}


susceptibility [15]. We directly sequenced the exons of $V D R$ and $C Y P 2 R 1$ in all 755 individuals and identified two mutations, specified as rs2228570 in exon 2 of $V D R$ and rs12794714 in exon 1 of CYP2R1. Sequencing $V D R$ and $C Y P 2 R 1$ genes was performed at the Beijing Genomics Institute (http://www.genomics.cn). DNAStar 5.0 SeqMan Software was used to identify DNA variants and provide genotype calls. The primers for PCR were designed by using Primer Premier 5.0 Software. Sequences of the primers are listed in Table 2.

We genotyped the two most commonly studied SNPs in the $G C$ gene, rs4588 and rs7041, using a standard PCR-restriction fragment length polymorphism (PCRRFLP). Genetic variants in $G C$ gene have been shown the different affinity in binding vitamin $\mathrm{D}$ metabolites [26]. The SNPs rs4588 and rs7041 have been found to have associations with several chronic lung diseases, such as COPD and tuberculosis [27,28]. Carriage of the genotype of Gc2 allele was associated with increased tuberculin-stimulated IFN- $\gamma$ release in Gujarati Asian TB contacts [27]. Homozygous carriers of the rs7041 $\mathrm{T}$ allele exhibited an increased risk for COPD in a Belgium population [28]. There are only 11 base pairs apart between these two SNPs in the human genome, however, they are not in the same LD block. Thus we selected these two important SNPs in our Chinese samples to test the association with the risk of developing asthma. These two SNPs, rs4588 and rs7041, are positioned at codons 416 (GAT $\rightarrow$ GAG, Asp $\rightarrow$ Glu) and 420 (ACG $\rightarrow$ AAG, Thr $\rightarrow$ Lys) of exon 11 of the GC gene (Table 3) [27]. The different loci were recognized by the following restriction

Table 2 Primer sequences and PCR conditions for genotyping VDR, CYP2R1 and GC variants

\begin{tabular}{|c|c|c|c|c|c|c|c|}
\hline Gene & Region & PCR primers $\left(5^{\prime} \rightarrow 3^{\prime}\right)$ & Sequencing primer $\left(5^{\prime} \rightarrow 3^{\prime}\right)$ & $\begin{array}{c}\text { Annealing } \\
\text { temperature }\left({ }^{\circ} \mathrm{C}\right)\end{array}$ & $\begin{array}{c}\text { PCR } \\
\text { product } \\
\text { (bp) }\end{array}$ & $\begin{array}{l}\text { Restriction } \\
\text { Enzyme }\end{array}$ & $\begin{array}{c}\text { RFLP } \\
\text { products } \\
\text { (bp) }\end{array}$ \\
\hline \multicolumn{8}{|l|}{$V D R$} \\
\hline & \multirow[t]{2}{*}{ Exon 1} & F:TGGCACCAAGGATGCCAGCT & & \multirow[t]{2}{*}{57} & \multirow[t]{2}{*}{364} & & \\
\hline & & R:TCCTGCTCCTGTGGCTGTGA & R:GTGAGCGCCGCATGTTCC & & & & \\
\hline & \multirow[t]{2}{*}{ Exon 2} & F:CCTCATGTCTTCTGTTGGAG & F:CCTCATGTCTTCTGTTGGAG & \multirow[t]{2}{*}{57} & \multirow[t]{2}{*}{438} & & \\
\hline & & R:TGCATCTGACCCTGGACTTC & & & & & \\
\hline & \multirow{2}{*}{$\begin{array}{l}\text { Exons } \\
3,4\end{array}$} & F: CCTATCTTGGACCTTTACCC & F: CCTATCTTGGACCTITACCC & 57 & \multirow[t]{2}{*}{758} & & \\
\hline & & R:TCCATTAGGGAGCCTTCCAC & & & & & \\
\hline & \multirow[t]{2}{*}{ Exon 5} & F: CTGTGGAGTCACTGTGGGAT & F: CTGTGGAGTCACTGTGGGAT & 57 & \multirow[t]{2}{*}{390} & & \\
\hline & & R:GAAGTGGTGGATGAGTGATC & & & & & \\
\hline & \multirow{2}{*}{$\begin{array}{l}\text { Exons } \\
6,7\end{array}$} & F: TGTTGGTGCCCAGCAGGTGT & F: TGTTGGTGCCCAGCAGGTGT & 57 & \multirow[t]{2}{*}{680} & & \\
\hline & & R:GCTACGTCTCCCTTCAGGTT & & & & & \\
\hline & \multirow[t]{2}{*}{ Exon 8} & F: TGCTGCCGTTGAGTGTCTGT & & \multirow[t]{2}{*}{57} & \multirow[t]{2}{*}{526} & & \\
\hline & & R:GGTTGGACAGGAGAGAGAAT & $\begin{array}{l}\text { R: } \\
\text { ACAGGAGAGAGAATGGGCTG }\end{array}$ & & & & \\
\hline \multicolumn{8}{|l|}{ CYP2R1 } \\
\hline & \multirow[t]{2}{*}{ Exon 1} & F:GGGACCTGAGGGTATCCTGC & $\begin{array}{l}\text { F: } \\
\text { ACCTGAGGGTATCCTGCCAATG }\end{array}$ & 55 & \multirow[t]{2}{*}{409} & & \\
\hline & & R:GGCGGCCATAAGTCCAACC & & & & & \\
\hline & \multirow[t]{2}{*}{ Exon 2} & F: AGGGACGTAACAAATCCTGG & F: AGAGCCGCACTTACCACTTG & 57 & \multirow[t]{2}{*}{412} & & \\
\hline & & R: GTAGTACAGCCTGAAAGGTC & & & & & \\
\hline & \multirow[t]{2}{*}{ Exon 3} & F: AACAGGACCCAACCATGTAG & $\begin{array}{l}\text { F: } \\
\text { GGAGGACAATTTGGAGAAGG }\end{array}$ & 57 & \multirow[t]{2}{*}{881} & & \\
\hline & & R: CATCGCAGGAGTTCCTAAAG & & & & & \\
\hline & \multirow[t]{2}{*}{ Exon 4} & F: TGGCTTGTTATAGGTTATCC & & 57 & \multirow[t]{2}{*}{574} & & \\
\hline & & R: CATTCTCTCCTGTTAGAATC & R: CATTCTCTCCTGTTAGAATC & & & & \\
\hline & \multirow[t]{2}{*}{ Exon 5} & F: GTTCTGCTTGCTGAAGTGTC & F: CATAGTTCCCTCTITCTTTG & 57 & \multirow[t]{2}{*}{415} & & \\
\hline & & R: ACCAAGTTCAGGGATAAGGC & & & & & \\
\hline \multicolumn{8}{|l|}{ GC } \\
\hline & \multirow[t]{2}{*}{$\begin{array}{l}\text { rs } 4588 \\
\text { rs } 7041\end{array}$} & $\begin{array}{l}\text { F: } \\
\text { AAATAATGAGCAAATGAAAGAAGAC }\end{array}$ & & 55 & \multirow[t]{2}{*}{483} & Hae III & 297/186 \\
\hline & & $\begin{array}{l}\text { R: } \\
\text { CAATAACAGCAAAGAAATGAGTAGA }\end{array}$ & & & & Sty 1 & $305 / 178$ \\
\hline
\end{tabular}


Table 3 Deduction of vitamin D binding protein genotypes from Haelll and Styl genotypes [27]

\begin{tabular}{|c|c|c|c|c|c|}
\hline $\begin{array}{l}\text { HaellI/Styl } \\
\text { Genotypes }\end{array}$ & $\begin{array}{l}\text { Potential } \\
\text { haplotypes }\end{array}$ & Deduced haplotypes & Corresponding DBP genotypes & Asthma (N) & $\begin{array}{l}\text { Control } \\
\text { (N) }\end{array}$ \\
\hline $\mathrm{HHSS}$ & $\mathrm{HS} / \mathrm{HS}$ & $\mathrm{HS} / \mathrm{HS}$ & Gc1F/Gc1F & 72 & 41 \\
\hline $\mathrm{HHSS}$ & $\mathrm{HS} / \mathrm{Hs}$ & $\mathrm{HS} / \mathrm{Hs}$ & Gc1F/Gc2 & 129 & 59 \\
\hline $\mathrm{HH}$ ss & $\mathrm{Hs} / \mathrm{Hs}$ & $\mathrm{Hs} / \mathrm{Hs}$ & $\mathrm{Gc} 2 / \mathrm{Gc} 2$ & 24 & 1 \\
\hline Hh SS & $\mathrm{HS} / \mathrm{hS}$ & $\mathrm{HS} / \mathrm{hS}$ & Gc1F/Gc1S & 93 & 46 \\
\hline Hh Ss & $\mathrm{Hs} / \mathrm{hS}$ or $\mathrm{HS} / \mathrm{hs}^{*}$ & $\mathrm{Hs} / \mathrm{hS}$ & Gc2/Gc1S & 71 & 35 \\
\hline $\mathrm{hh} / \mathrm{SS}$ & $\mathrm{hS} / \mathrm{hS}$ & $\mathrm{hS} / \mathrm{hS}$ & Gc1S/Gc1S & 27 & 18 \\
\hline $\mathrm{Hh} / \mathrm{Ss}$ & $h S / h s^{*}$ & Gc1s/not deduced & Not assigned & 0 & 0 \\
\hline
\end{tabular}

*frequency of the hs haplotype is very low due to linkage disequlibrum between loci

endonucleases (New England Biolabs): Hae III for T/G at $37^{\circ} \mathrm{C}$, Sty I for $\mathrm{C} / \mathrm{A}$ at $37^{\circ} \mathrm{C}$.

The PCR reactions were performed in a total volume of $30 \mu \mathrm{l}$ (40 ul for $G C$ variants genotyping) containing $70 \mathrm{ng}$ of genomic DNA, $3 \mu \mathrm{l}$ of $10 \times$ PCR Buffer, 1.5 $\mu \mathrm{M}$ of $\mathrm{MgCl}_{2}, 0.17 \mathrm{mM}$ of dNTPs, $100 \mathrm{pM}$ of each primer, and $1.5 \mathrm{U}$ of Taq DNA polymerase (Takara). In general, PCR cycle condition consisted of an initial denaturation step at $94^{\circ} \mathrm{C}$ for 3 min followed by 30 cycles (35 cycles for $\mathrm{GC}$ variants genotyping) of denaturation for $30 \mathrm{~s}$ at $94^{\circ} \mathrm{C}$, annealing for $30 \mathrm{~s}$ at $55-57^{\circ} \mathrm{C}$, extension for $40-45 \mathrm{~s}$ at $72^{\circ} \mathrm{C}$, and a final extension at $72^{\circ} \mathrm{C}$ for $7 \mathrm{~min}$.

\section{Statistical analysis}

Because of similar functional characteristics of $G C$ isoforms Gc1F and Gc1S, allele carriers were combined to produce a total of 3 genotypes: Gc1/1, Gc1/2 and Gc2/ 2. Allele and genotype frequencies of polymorphisms in $V D R, C Y P 2 R 1$ and $G C$ were obtained by direct counting, and Hardy-Weinberg equilibrium was evaluated by a chi-squared test (using SPSS statistical software, version 12.0). All genotype and phenotype data were formatted using PLINK.

Quantitative traits were tested using a variance components approach implemented in the statistical package Merlin [29]. Quantile normalization was applied to all quantitative traits prior to analysis (with the exception of total serum IgE which had already been subjected to a log transformation). Missing genotypes were inferred using the - infer option available in Merlin.

In addition, an unpaired t-test was used to compare the baseline data between asthma patients and healthy controls. One-way ANONA was used to assess the genotype distribution in asthma patients. A Bonferroni correction was used to adjust $\mathrm{p}$-values for multiple testing (based on an alpha threshold of 0.05). Genotype and allele frequencies in cases and controls were also compared by contingency table analysis. Genotype relative risk was calculated according to the statistical method described by Lathrop [30]. This method compares case genotype frequencies with expected control genotype frequencies under the assumption of Hardy-Weinberg equilibrium, and is more powerful than standard contingency table analysis.

\section{Results}

We genotyped 1 SNP (rs12794714) in CYP2R1, 1 SNP (rs2228570) in VDR, and 2 SNPs (rs4588 and rs7041) in GC. The allele and genotype frequencies are listed in Table 4. All SNPs met criteria for Hardy-Weinberg equilibrium in both case and control groups (all p-value $>0.05$ ).

No significant difference was observed in the genotype and allele frequencies of rs2228570 in $V D R$ and rs12794714 in CYP2R1 between asthmatic cases and controls (Table 4), suggesting that these SNPs were not genetically associated with the risk of asthma.

Importantly, single marker analysis of association showed that $G C$ polymorphism (expressed as Gc1/1, Gc1/2 and Gc2/2) was significantly associated with asthma susceptibility in our Chinese samples, the risk conferred by it was slightly elevated $(\mathrm{OR}=1.35,95 \% \mathrm{CI}$ $=1.01-1.78, \mathrm{P}=0.006)$. Compared with $\mathrm{Gc1} 1 / 1$ genotype, Gc2/2 genotype was strongly associated with the risk of asthma $(\mathrm{OR}=13.13,95 \% \mathrm{CI}=2.42-7.13, \mathrm{P}=$ 0.001 ) (Table 4). These results may suggest that Gc2/2 genotype confers a significant risk for developing asthma.

Vitamin D deficiency has been defined as serum $25 \mathrm{OHD}<50 \mathrm{nmol} / \mathrm{l}$ [31]. We have previously demonstrated that vitamin D deficiency is common among Chinese patients with asthma [12]. Thus, we retrospectively analysed the association between the $G C$ polymorphisms and serum 25-OHD concentrations, however, no significant difference was observed (Table 5).

We further examined the evidence for association between the polymorphic markers in these three genes and a number of quantitative asthma-related traits using Merlin. We were not able to demonstrate any significant associations between the studied SNPs and blood eosinphil counts, log-transformed serum IgE or lung function 
Table 4 Association between asthma and polymorphisms of CYP2R1, VDR, GC genes

\begin{tabular}{|c|c|c|c|c|c|}
\hline & Genotype/Allele & $\begin{array}{c}\text { Asthmatics, } \\
\text { n (\%) }\end{array}$ & Controls, n (\%) & $\chi^{2}$ & $P$ \\
\hline \multicolumn{6}{|l|}{ VDR rs 2228570} \\
\hline & CC & 152 & 60 & & \\
\hline & CT & 230 & 91 & & \\
\hline & $\pi$ & 85 & 37 & 0.194 & 0.908 \\
\hline & C & $534(57.2)$ & $211(56.1)$ & & \\
\hline & $\mathrm{T}$ & $400(42.8)$ & $165(43.9)$ & 0.122 & 0.727 \\
\hline \multicolumn{6}{|l|}{ CYP2R1 rs 12794717} \\
\hline & $\mathrm{CC}$ & 171 & 64 & & \\
\hline & CT & 214 & 86 & & \\
\hline & $\pi$ & 81 & 25 & 1.02 & 0.601 \\
\hline & C & $556(59.7)$ & $214(61.1)$ & & \\
\hline & $\mathrm{T}$ & $376(40.3)$ & $136(38.9)$ & 0.234 & 0.628 \\
\hline \multicolumn{6}{|l|}{ GC } \\
\hline & $\mathrm{Gc} 1 / 1$ & 192 & 105 & & \\
\hline & $\mathrm{Gc} 1 / 2$ & 200 & 94 & & \\
\hline & $G c 2 / 2$ & 24 & 1 & 10.401 & 0.006 \\
\hline & Gc1 & $584(70.2)$ & $304(76.0)$ & & \\
\hline & Gc2 & $248(29.8)$ & $96(24.0)$ & 4.527 & 0.033 \\
\hline
\end{tabular}

measures, even after stratification by sex (data not shown).

\section{Discussion}

We performed a case-control study assessing association between polymorphisms in 3 genes of the vitamin D pathway and asthma susceptibility in the Chinese Han population. We showed that the $G C$ polymorphisms giving rise to the major electrophoretic isoforms of vitamin E binding protein (rs4588 and rs7041) were significantly associated with the risk of asthma, although not 25OHD concentrations in asthma patients. By sequencing all

Table 5 Frequency of genotypes of CYP2R1, VDR, DBP in asthmatics with different vitamin $D$ status

\begin{tabular}{|c|c|c|c|c|c|}
\hline \multirow[t]{3}{*}{ Serum 25OHD } & \multirow[t]{3}{*}{ Subjects, n } & \multicolumn{3}{|c|}{ Genotypes, n (\%) } & \multirow[t]{2}{*}{$P$ value } \\
\hline & & \multicolumn{3}{|c|}{ CYP2R1 rs12794717 } & \\
\hline & & $\mathrm{CC}$ & $\mathrm{CT}$ & $\mathrm{TT}$ & \\
\hline$\geq 50 \mathrm{nmo} \mathrm{l} / \mathrm{L}$ & 49 & $20(40.8)$ & $24(49)$ & $5(10.2)$ & \\
\hline$<50 \mathrm{nmol} / \mathrm{L}$ & 363 & $132(36.4)$ & $167(46)$ & 64 (17.6) & 0.42 \\
\hline
\end{tabular}

\begin{tabular}{clcccc} 
& \multicolumn{5}{c}{$V D R \quad$ rs2228570 } \\
& \multicolumn{1}{c}{ CC } & $C T$ & $\pi$ & \\
\hline$\geq 50 \mathrm{nmol} / \mathrm{L}$ & 49 & $13(26.5)$ & $25(51.1)$ & $11(22.4)$ & \\
$<50 \mathrm{nmol} / \mathrm{L}$ & 362 & $124(34.3)$ & $180(49.7)$ & $58(16)$ & 0.397
\end{tabular}

\begin{tabular}{llcccc} 
& & \multicolumn{4}{c}{ GC rs4588 and rs7041 } \\
& & Gc1/1 & Gc1/2 & Gc2/2 & \\
\hline$\geq 50 \mathrm{nmol} / \mathrm{L}$ & 49 & $20(40.8)$ & $26(53.1)$ & $3(6.1)$ & \\
$<50 \mathrm{nmol} / \mathrm{L}$ & 363 & $169(46.5)$ & $173(47.7)$ & $21(5.8)$ & 0.747 \\
\hline
\end{tabular}

exons of $V D R$ and $C Y P 2 R 1$ genes, we have identified that the full range of exonic genetic variants presented in our cohort have shown allele frequencies $\geq 0.13 \%$. We observed only two exonic SNPs, rs2228570 (also known as Fok I) in VDR and rs12794714 in CYP2R1, both of which had been previously characterised. No association could be identified between either of these SNPs and asthma. Because exonic regions are more likely to carry variants that disrupt protein function [32,33], our polymorphism screening did not include intronic or promoter regions of these genes which may also potentially contain causal variants [34].

The FokI polymorphism in exon 2 of $V D R$ consists of a $\mathrm{T}$ to $\mathrm{C}$ change which has been reported to cause gene-specific and cell type-specific effects. VDR polymorphisms have been widely studied in asthma, and the results have been contradictory $[15,18-23]$. The association of polymorphisms in $V D R$ with asthma was first reported in Northern American family-based studies $[19,20]$, but initial positive results were not replicated in subsequent populations $[22,23]$. Consistent with our negative results, a previous case-control study of rs2228570 performed in a Chinese Han population also failed to show an association with asthma [21].

The CYP2R1 variant, rs12794714, has previously been associated with serum 25OHD levels in a healthy Caucasian population [35]. Alternative $C Y P 2 R 1$ variants have also been implicated in asthma susceptibility, though these effects have not replicated consistently among populations [15]. This lack of consistency may reflect a linkage disequilibrium phenomenon (with non-coding 
regulatory variants(s)), a consequence of complex, undefined gene-gene (epistatic) or gene-environment interactions, or a low magnitude effect requiring large, highly powered cohorts for its detection.

The vitamin $\mathrm{D}$ binding protein (DBP), encoded by $G C$, is the principle plasma carrier protein of vitamin $\mathrm{D}$ and its metabolites. Due to a higher binding affinity of Gc1F and Gc1S to 25OHD, the isoforms are hypothesized to deliver 25OHD to target tissues more efficiently than Gc2 [26]. The results presented here indicate that the two common SNPs in $G C$ which determine DBP isoforms associate significantly with susceptibility to asthma, and that the Gc1 allele might confer a protective effect. One previous study of $G C$ variants in asthma did not find an association, however, this study included a very small number of participants and was probably underpowered to detect a difference [17].

Polymorphisms in $G C$ gene have been found to be significantly associated with 25OHD concentrations by genome-wide association (GWA) [36,37]. We have previously shown that lower serum 25OHD concentrations are associated with impaired lung function measurements in Chinese patients with asthma [12]. In this study, we reported the association between genetic variants in $G C$ and asthma susceptibility. Thus, we further investigated the influence of $G C$ genotypes on serum 25-OHD concentrations in asthma patients. When performing multiple tests for the association analysis with Bonferroni correction to the dataset, we couldn't find any significant association. One explanation could be that circulating serum 25OHD concentrations are influenced by several genetic loci $[36,37]$.

\section{Conclusion}

In conclusion, this study has shown that genetic variants in the gene encoding the vitamin $\mathrm{D}$ binding protein $(G C)$ contribute to asthma susceptibility in a Han Chinese population. The OR in this study with respect to Gc2/2 homozygote suggests a modest but definite genetic effect. We have not found associations between that exonic variants in the $V D R$ and $C Y P 2 R 1$ genes and asthma or asthma-related traits in our Chinese population. Further research is needed to understand how gene-gene or gene-environment interactions and causative regulatory variants (intronic, promoter, or trans-acting) influence vitamin D metabolism in asthma patients [34].

\section{Acknowledgements}

This work was funded by New Century Excellent Talents program from Education Ministry of China (NCET-06-0156) and a grant from National Natural Sciences Foundation of China (No.30470767).

\section{Author details}

'Department of Respiratory Diseases, Peking Union Medical College Hospital, Peking Union Medical College \& Chinese Academy of Medical Sciences, Beijing 100730, China. ${ }^{2}$ Molecular Genetics and Genomics, National Heart and Lung Institute, Imperial College London, London, UK.

\section{Authors' contributions}

$\mathrm{FL}$ performed the whole procedure of the experiments. $L J$ helped in performing the experiment. SAWO and YZh performed the statistical analysis and drafted the manuscript. JG designed and supervised the experiment, and drafted the manuscript. all authors read and approved the final manuscript.

\section{Competing interests}

The authors declare that they have no competing interests.

Received: 15 March 2011 Accepted: 3 August 2011

Published: 3 August 2011

\section{References}

1. Willis-Owen SA, Cookson WO, Moffatt MF: Genome-wide association studies in the genetics of asthma. Curr Allergy Asthma Rep 2009, 9(1):3-9.

2. Vercelli D: Discovering susceptibility genes for asthma and allergy. Nat Rev Immunol 2008, 8(3):169-82.

3. Ober C, Hoffjan S: Asthma genetics 2006: the long and winding road to gene discovery. Genes Immun 2006, 7(2):95-100.

4. Devereux $G$, et al: A case-control study of vitamin $D$ status and asthma in adults. Allergy 65(5):666-7.

5. Brehm JM, et al: Serum vitamin D levels and markers of severity of childhood asthma in Costa Rica. Am J Respir Crit Care Med 2009, 179(9):765-71.

6. Brehm $\mathrm{JM}$, et al: Serum vitamin $\mathrm{D}$ levels and severe asthma exacerbations in the Childhood Asthma Management Program study. J Allergy Clin Immunol 126(1):52-8 e5.

7. Searing $D A$, et al: Decreased serum vitamin $D$ levels in children with asthma are associated with increased corticosteroid use. J Allergy Clin Immunol 125(5):995-1000.

8. Shaheen SO: Vitamin D deficiency and the asthma epidemic. Thorax 2008, 63(3):293, author reply 293.

9. Devereux $G$, et al: Low maternal vitamin $E$ intake during pregnancy is associated with asthma in 5-year-old children. Am J Respir Crit Care Med 2006, 174(5):499-507.

10. Litonjua $A A$, et al: Maternal antioxidant intake in pregnancy and wheezing illnesses in children at 2 y of age. Am J Clin Nutr 2006, 84(4):903-11.

11. Camargo CA Jr, et al: Maternal intake of vitamin D during pregnancy and risk of recurrent wheeze in children at 3 y of age. Am J Clin Nutr 2007, 85(3):788-95.

12. Li F, et al: Vitamin d deficiency is associated with decreased lung function in chinese adults with asthma. Respiration 81(6):469-75.

13. Sutherland $E R$, et al: Vitamin $D$ levels, lung function, and steroid response in adult asthma. Am J Respir Crit Care Med 181(7):699-704.

14. Majak $P$, et al: Vitamin D supplementation in children may prevent asthma exacerbation triggered by acute respiratory infection. J Allergy Clin Immunol 127(5):1294-6.

15. Bosse $Y$, et al: Asthma and genes encoding components of the vitamin $D$ pathway. Respir Res 2009, 10:98.

16. Chishimba $L$, et al: The vitamin $D$ axis in the lung: a key role for vitamin D-binding protein. Thorax 2010, 65(5):456-62.

17. Laufs J, et al: Association of vitamin $D$ binding protein variants with chronic mucus hypersecretion in Iceland. Am J Pharmacogenomics 2004, 4(1):63-8.

18. Fang WL, et al: Association analysis of vitamin $D$ receptor gene polymorphisms in chinese population with asthma. Iran J Allergy Asthma Immunol 2009, 8(3):141-7.

19. Raby $B A$, et al: Association of vitamin $D$ receptor gene polymorphisms with childhood and adult asthma. Am J Respir Crit Care Med 2004, 170(10):1057-65.

20. Poon $\mathrm{AH}$, et al: Association of vitamin $\mathrm{D}$ receptor genetic variants with susceptibility to asthma and atopy. Am J Respir Crit Care Med 2004, 170(9):967-73. 
21. Saadi A, et al: Association study between vitamin D receptor gene polymorphisms and asthma in the Chinese Han population: a casecontrol study. BMC Med Genet 2009, 10:71.

22. Vollmert $C$, et al: Single nucleotide polymorphism screening and association analysis-exclusion of integrin beta 7 and vitamin $D$ receptor (chromosome 12q) as candidate genes for asthma. Clin Exp Allergy 2004, 34(12):1841-50.

23. Wjst M: Variants in the vitamin D receptor gene and asthma. BMC Genet 2005, 6:2.

24. Gao J, et al: Polymorphisms of PHF11 and DPP10 are associated with asthma and related traits in a Chinese population. Respiration 79(1):17-24.

25. Bateman ED, et al: Global strategy for asthma management and prevention: GINA executive summary. Eur Respir J 2008, 31(1):143-78.

26. Arnaud J, Constans J: Affinity differences for vitamin D metabolites associated with the genetic isoforms of the human serum carrier protein (DBP). Hum Genet 1993, 92(2):183-8.

27. Martineau AR, et al: Association between Gc genotype and susceptibility to TB is dependent on vitamin D status. Eur Respir J 35(5):1106-12.

28. Janssens $W$, et al: Vitamin D deficiency is highly prevalent in COPD and correlates with variants in the vitamin D-binding gene. Thorax 65(3):215-20.

29. Abecasis GR, et al: Merlin-rapid analysis of dense genetic maps using sparse gene flow trees. Nat Genet 2002, 30(1):97-101.

30. Lathrop GM: Estimating genotype relative risks. Tissue Antigens 1983, 22(2):160-6.

31. Holick MF: Vitamin D deficiency. N Engl J Med 2007, 357(3):266-81.

32. Cotton RG, Scriver CR: Proof of "disease causing" mutation. Hum Mutat 1998, 12(1):1-3.

33. Kryukov GV, Pennacchio LA, Sunyaev SR: Most rare missense alleles are deleterious in humans: implications for complex disease and association studies. Am J Hum Genet 2007, 80(4):727-39.

34. Loots $\mathrm{GG}$, et al: Identification of a coordinate regulator of interleukins 4 , 13 , and 5 by cross-species sequence comparisons. Science 2000, 288(5463):136-40.

35. Bu FX, et al: Comprehensive association analysis of nine candidate genes with serum 25-hydroxy vitamin D levels among healthy Caucasian subjects. Hum Genet 2010, 128(5):549-56.

36. Wang TJ, et al: Common genetic determinants of vitamin D insufficiency: a genome-wide association study. Lancet 376(9736):180-8.

37. Ahn J, et al: Genome-wide association study of circulating vitamin D levels. Hum Mol Genet 19(13):2739-45

\section{Pre-publication history}

The pre-publication history for this paper can be accessed here: http://www.biomedcentral.com/1471-2350/12/103/prepub

doi:10.1186/1471-2350-12-103

Cite this article as: Li et al:: Vitamin D binding protein variants associate with asthma susceptibility in the Chinese han population. BMC Medical Genetics 2011 12:103.

\section{Submit your next manuscript to BioMed Central and take full advantage of:}

- Convenient online submission

- Thorough peer review

- No space constraints or color figure charges

- Immediate publication on acceptance

- Inclusion in PubMed, CAS, Scopus and Google Scholar

- Research which is freely available for redistribution

Submit your manuscript at www.biomedcentral.com/submit
Biomed Central 